\title{
A CONSTRUÇÃO DAASSISTÊNCIA À SAÚDE MENTAL EM DUAS UNIDADES DE SAÚDE DA FAMÍLIA DE CUIABÁ-MT
}

Carolina Campos Ribeiro ${ }^{1}$, Lorena Araújo Ribeiroํㅜ, Alice G. Bottaro de Oliveira²

\begin{abstract}
RESUMO: O Programa Saúde da Família e a Reforma Psiquiátrica prevêem a mudança de modelo assistencial superando práticas médico-curativas. Analisar a dinâmica assistencial à saúde mental em duas unidades do Programa Saúde da Família-PSF de Cuiabá-MT foi o objetivo desta pesquisa de abordagem qualitativa. A análise de conteúdo identificou três categorias: territorialidade, recursos e vínculo dos serviços; processo de trabalho das equipes; rede assistencial em saúde mental. Os resultados mostram a dificuldade de acesso, infra-estrutura precária e vínculo frágil das unidades com a comunidade. Havia demanda de transtornos mentais nas duas unidades, porém somente em uma houve uma aproximação do trabalho articulado à promoção da saúde mental na comunidade. A rede de referência em saúde mental destas unidades se mostrou desarticulada. Há necessidade de investimentos técnico-assistenciais e políticos para consolidar a atenção aos portadores de transtornos mentais no PSF.
\end{abstract}

PALAVRAS-CHAVE: Saúde da família; Saúde mental; Enfermagem; Trabalho.

\section{THE CONSTRUCTION OF MENTAL HEALTH ASSISTANCE AT TWO FAMILY HEALTH UNITS IN CUIABÁ-MATO GROSSO STATE/BRAZIL}

\begin{abstract}
The Family Health Program and the Psychiatric Reform foresee a change in the caring model, surpassing the medical curing practices. This research study, with a qualitative approach, objectified to analyze mental health caring dynamics at two units of the Family Health Program in Cuiabá, Mato Grosso State/Brazil. Content analysis identified three categories: unit coverage area, resources and services link; teams' work process and mental health care network. The results evidenced access difficulties, a precarious infra-structure and fragile bonds between the units and the community. There was a caring demand of mental disorders in the two units, however in only one of them work organization articulated mental health promotion within the community. The reference mental health network proved to be disarticulated in those units. There is a need of investments in technical assistance and policies to consolidate mental health care in the Family Health Program.
\end{abstract}

KEYWORDS: Family health; Mental health; Nursing; Work.

\section{LA CONSTRUCCIÓN DE LAASISTENCIAA LA SALUD MENTALEN DOS UNIDADES DE SALUD DE LA FAMILIA DE CUIABÁ-MATO GROSSO}

RESUMEN: El Programa Salud de la Familia (PSF) y la Reforma psiquiátrica prevén un cambio de modelo de atención que es la superación de prácticas médico-curativas. Examinar la dinámica de atención a la salud mental en dos unidades de PSF de Cuiabá, MT fue el objetivo de esta investigación, de foque cualitativo. El análisis de contenido fue identificado en tres categorías: la territorialidad, los recursos y la relación de servicios; proceso de trabajo de los equipos; red de atención de la salud mental; los resultados muestran la dificuldad de acceso, la precariedad de la infraestructura y vínculo frágil de las unidades con la comunidad. Hubo demanda de los trastornos mentales en los dos, pero solamente en una la organización del trabajo articulava la promoción de la salud mental en la comunidad. La red de referencia en salud mental fue desarticulada de las unidades estudiadas. Hay necesidades de iversiones técnico-asistenciales y políticas para consolidar la atención de los titulares de molestias mentales en el PSF.

PALABRAS CLAVE: Salud de la familia; Salud mental; Enfermería; Trabajo.

${ }^{1}$ Enfermeiras. Mestrandas do Programa de Pós-Graduação em Enfermagem. Universidade Federal de Mato Grosso -UFMT. ${ }^{2}$ Enfermeira. Doutora. Professora Associada. Faculdade de Enfermagem. Universidade-FAEN-UFMT. Líder do Grupo de Pesquisa Núcleo de Estudos em Saúde Mental - NESM-MT.

Autor correspondente:

Alice G. Bottaro de Oliveira

Rua Pres. Rodrigues Alves, 99 - 78043-418 - Cuiabá-MT

Recebido: 06/06/08

E-mail: alicegbo@yahoo.com.br

Aprovado: 08/11/08

Cogitare Enferm 2008 Out/Dez; 13(4):548-57 


\section{INTRODUÇÃO}

Com a implantação do Sistema Único de Saúde (SUS) no Brasil, ocorreram mudanças significativas nas dimensões política e assistencial do sistema de saúde. A participação aliada a outros princípios, em que se destacam a integralidade e descentralização, desencadearam mudanças em todas as áreas assistenciais.

O Programa Saúde da Família (PSF), no início da década de 90, surgiu como alternativa e estratégia técnica-política para a mudança do modelo assistencial no SUS. Sua efetivação requer mudanças relacionadas à autonomia, direitos, participação, além das práticas de saúde, para gestores, trabalhadores e usuários do SUS. A singularidade dos sujeitos, a interação na família e os aspectos objetivos e subjetivos do território são importantes nesta estratégia ${ }^{(1)}$.

No campo de atenção à saúde mental também se processaram modificações no modelo assistencial nas últimas décadas, até então centrado na psiquiatria médica e asilar, que passou a ser questionado pelo movimento da reforma psiquiátrica ${ }^{(2)}$.

A reforma psiquiátrica insere-se na superação paradigmática com abertura de um novo contexto prático-discursivo sobre a loucura e o sofrimento humano no campo das teorias e do conhecimento, buscando ainda reorganizar o modelo assistencial para que possibilite a reconstrução da cidadania, dos direitos humanos e sociais do sujeito em sofrimento mental(3).

Na reforma psiquiátrica a relação entre a família e o sujeito em sofrimento mental é de singular importância, sendo umas das estratégias do cuidado psicossocial a criação de dispositivos comunitários de cuidado de saúde mental, como os Centros de Atenção Psicossocial (CAPS), e sua articulação em rede com os serviços de saúde, principalmente o PSF, devido à sua inserção nas comunidades e de ter a família como foco de atenção $0^{(2)}$.

A finalidade do cuidado psicossocial é a reconstrução das pessoas como sujeitos sociais em suas múltiplas dimensões existenciais e não mais somente a remoção dos sintomas; a emancipação, a ampliação do poder de trocas sociais do portador de transtorno mental e o fortalecimento dos laços de sociabilidade na família são objetivos do cuidado psicossocial que se constrói cotidianamente ${ }^{(3-4)}$.

Neste panorama evidencia-se a importância do PSF no cuidado ao portador de transtorno mental, pois ele pressupõe a integralidade nas práticas de cuidado à saúde e, segundo alguns autores, a saúde mental é o "fiel da balança" que permite avaliar o grau de integralidade mínimo do cuidado realizado no $\mathrm{PSF}^{(5)}$.

Apesar da tradição de não inclusão de cuidados aos portadores de transtorno mental no nível primário de atenção à saúde, atualmente, a parceria do PSF com a assistência à saúde mental produz um conjunto de ações que extrapolam o caráter médicoassistencialista e reforçam a produção de inclusão social e garantia de uma rede de cuidados ao portador de transtorno mental ${ }^{(2-3,6)}$.

Estudos apontam uma alta prevalência de transtornos mentais não psicóticos que acometem a população e que acarretam sofrimento, incapacidade funcional e implicações socioeconômicas, para os quais o PSF tem grande potencial resolutivo ${ }^{(7)}$.

Nessa perspectiva, PSF e reforma psiquiátrica convergem na luta por direitos de cidadania, por ações que contemplem o ser humano de forma integral e integrada na sociedade. Refletir sobre a trajetória dessa integração, numa dada realidade, com o objetivo de potencializar as estratégias de cuidado, que estão se efetivando em todo o País nessa área, é a justificativa deste estudo que pretende contribuir para o conhecimento dos limites e possibilidades das equipes de PSF desenvolverem atenção à saúde mental.

O objetivo deste estudo foi analisar a dinâmica assistencial à saúde mental em duas unidades de PSF de Cuiabá-MT e, especificamente, descrever os recursos materiais (estrutura física) e não materiais (acesso e acolhimentos) das unidades de PSF tendo em vista as necessidades da atenção psicossocial; identificar situações que demandaram assistência à saúde mental; e analisar o modo de inclusão de pessoas e famílias em sofrimento mental no processo de trabalho/cuidado e a relação desse trabalho/cuidado com os outros níveis da rede de saúde no município.

\section{METODOLOGIA}

Pesquisa exploratório-descritiva realizada em duas unidades de PSF do município de Cuiabá-MT, denominadas neste artigo A e B. As equipes de ambas participaram de uma capacitação em saúde mental realizada no ano de 2004, pela Secretaria Municipal de Saúde de Cuiabá, em convênio com a Faculdade de Enfermagem da UFMT.

O referencial teórico-metodológico situa-se nos estudos de Mendes-Gonçalves ${ }^{(8)}$ sobre o processo de trabalho em saúde na perspectiva dialética-marxista, 
na qual se evidencia que os elementos do processo de trabalho (objeto, finalidades e meios), assim como os modelos assistenciais, são históricos e devem ser compreendidos na totalidade de uma realidade material complexa e dinâmica que condiciona, inclusive, as subjetividades dos sujeitos envolvidos (trabalhadores, usuários, familiares).

Não sendo "naturais", as necessidades de saúde são percebidas de modo historicamente singular ${ }^{(8)}$. A "loucura" foi durante séculos, abordada nos hospícios longe das cidades e, atualmente, as equipes de PSF, pela sua integração nas comunidades, são requisitadas como espaços privilegiados de intervenção nos "transtornos mentais" da população.

Mais do que os nomes foram modificados nesse processo: as necessidades são construídas/ reconhecidas historicamente e à medida que se aprofunda a divisão do trabalho e convive-se com um grau mais complexo de socialização, as práticas de saúde também se modificam, incorporando, dialeticamente, o meio, a cidade, a cultura e os comportamentos de modo peculiar ${ }^{(8)}$.

A autonomia e a participação de usuários, familiares e trabalhadores, princípios da atenção psicossocial $^{(2-3)}$ também foram conceitos norteadores da análise. Todavia, esses conceitos são tomados na dimensão do processo de trabalho em saúde que, não produzindo mercadorias e abordando o ser humano como seu “objeto", inclui (objetivamente), os aspectos subjetivos de ambos -trabalhador e usuário/familiar-, como os desejos, intenções, afetos, normas e atividades do trabalho em si. Desse modo, ambos serão sujeitos em permanente "criação", pois se produzem no cotidiano das práticas de saúde ${ }^{(8)}$.

A coleta de dados foi realizada em junho e julho de 2006, por meio de entrevistas, observação e análise de documentos (prontuários e Sistema de Informação da Atenção Básica - SIAB) depois da aprovação da pesquisa no Comitê de Ética em Pesquisa (No 176/ CEP-HUJM/2004). Os participantes assinaram um Termo de Consentimento Livre e Esclarecido, após abordagem do pesquisador e antes da entrevista, em que se garantiu sigilo, anonimato e desistência da participação a qualquer momento.

Foram entrevistados dois enfermeiros, um médico, 12 agentes comunitários de saúde (ACS) e dois técnicos em enfermagem. As entrevistas foram gravadas e transcritas; são apresentados fragmentos de falas dos entrevistados identificados em ordem numérica aleatória, como profissionais de $\mathrm{n}^{\circ} 1$ a 17 .
As entrevistas enfocaram a percepção dos profissionais sobre a demanda de saúde mental nas unidades e o cuidado realizado.

A observação teve por objetivo visualizar o cenário físico das unidades de PSF, dos sujeitos, das ações, das atitudes profissionais, das relações entre os profissionais e dos usuários no serviço, além da dinâmica de funcionamento e organização do trabalho. A observação participante foi limitada aos objetivos do estudo e realizada durante uma semana. $\mathrm{O}$ relato da observação será identificado neste estudo, pela letra "R”, seguida da letra “O” (RO).

A análise dos dados visou contemplar os dados empíricos em todas as suas particularidades e articulálos, estabelecendo relações entre o material empírico e bibliográfico. Com base na técnica de Análise de Conteúdo conforme apresentada por Bardin ${ }^{(9)}$, foram identificadas as unidades de registros que, relacionadas com os marcos teóricos deste estudo, resultaram nas seguintes categorias: territorialidade, recursos e vinculação do serviço com a comunidade; processo de trabalho das equipes; e, a relação com os outros níveis da rede assistencial de cuidados em saúde mental.

\section{APRESENTAÇÃO E DISCUSSÃO DOS DADOS}

Territorialidade, recursos materiais (estrutura física) e não materiais (acesso e acolhimentos) nas unidades

O PSF foi implantado com a intenção de alterar o paradigma de atenção à saúde, da assistência individual para a família. Segundo a Portaria nº . 1886/ GM/1997 do Ministério da Saúde (MS), que aprova as normas e diretrizes do PSF, este consiste em unidade ambulatorial pública de saúde destinada a realizar assistência contínua, através de uma equipe multiprofissional mínima, de um médico generalista, um enfermeiro, um auxiliar de enfermagem e ACS na proporção de um para no máximo 150 famílias ou 750 pessoas.

Para que as ações se realizem do modo previsto, o PSF obedece a algumas diretrizes operacionais, entre elas a noção de territorialidade, que o coloca como responsável por uma área de abrangência e a adscrição da clientela, composta por 600 a 1000 famílias em um determinado território ${ }^{(10)}$.

Neste modelo de organização, este quantitativo visa garantir a interação com as redes familiares e sociais dos usuários, a construção de vínculos comunitários e facilitar as intervenções assistenciais 
em sua complexidade biopsicossosial. A acessibilidade geográfica permite a formação de parcerias que facilitam o atendimento, uma vez que a assistência deve se realizar no âmbito familiar e sócio-ambiental. O PSF “A” atendia a 1021 famílias e possuía localização centralizada em prédio germinado a outra unidade de PSF; o PSF “B” tinha como referência 1108 famílias. Portanto, ambas tinham um número de famílias maior que o recomendado pelo MS e se localizavam distantes da comunidade adscrita.

O excessivo número de famílias, além de outros obstáculos, tem sido freqüente para a expansão e qualificação do PSF que, muitas vezes é implantado com recursos escassos, improvisados, pois o valor atribuído ao trabalho é seletivo, na lógica de serviços simples para regiões e pessoas pobres ${ }^{(11)}$. Neste sentido, na unidade A, observamos a falta de mobiliários básicos como cadeiras na sala de espera, materiais de higiene nos banheiros, ausência de água potável para o consumo, atendimentos realizados com porta de consultório aberto devido à fechadura estragada, e préconsulta sendo realizada na farmácia devido à ausência de sala para o procedimento. São situações que interferem na qualidade do atendimento num serviço de atenção à saúde, visto que não atende ao mínimo de conforto, privacidade, higiene e hidratação das pessoas e compromete o acolhimento.

O PSF "B" funcionava em um imóvel alugado, originalmente quitinete e adaptado. Apesar de possuir salas amplas e arejadas, identificamos uma estrutura pouco acolhedora e que não permitia a circulação e interação entre os usuários e destes com a equipe.

A influência da precária infra-estrutura do PSF "A" ficou evidente durante um atendimento a um usuário com transtorno mental em crise:

\section{[...] o primeiro contato com um portador de} sofrimento mental (alcoolizado) se deu na sala de espera comum a todos os demais usuários que aguardavam consultas. Ele foi abordado pelo profissional $n^{\circ} 2$ que perguntou ali mesmo, pois não havia uma sala ou consultório disponível para abordagem, qual era o problema [...]” (RO).

A distância da comunidade foi referida por alguns profissionais como uma limitação ao trabalho, pois impedia que se deslocassem na comunidade e desenvolvessem práticas de prevenção e promoção da saúde integradas com os recursos comunitários; muitas visitas domiciliares também não eram feitas devido à necessidade de carro para o deslocamento. Do mesmo modo, o acesso dos usuários às unidades também era dificultado pela distância, principalmente para pessoas idosas, gestantes, deficientes físicos e portadores de transtornos mentais. Desse modo, um princípio básico do PSF, a facilidade de acesso pela inserção da unidade na comunidade adscrita, não era respeitado nas unidades estudadas e implicava em problemas para a assistência que pressupõe a atenção comunitária. Neste caso, a assistência contínua, de base territorial e a abordagem intersetorial na promoção da saúde e prevenção de doenças, princípios do $\operatorname{PSF}^{(1,10)}$, têm poucas possibilidades de serem viabilizadas.

No PSF é necessário considerar a adequação dos serviços ao ambiente e à cultura local, respeitando a individualidade e a privacidade dos clientes. A ambiência é marcada tanto por tecnologias assistenciais, como por outros componentes estéticos ou sensíveis captados pelo olhar, olfato, audição, como por exemplo, luminosidade, os ruídos e a temperatura, que também influenciam na qualidade da assistência oferecida ${ }^{(12)}$.

$\mathrm{Na}$ atenção à saúde mental, esses elementos expressos na forma de acolhimento, na atenção dispensada, na interação entre os trabalhadores, propiciam bem-estar do usuário, uma vez que a pessoa quando se reconhece no ambiente, se sente mais segura para expressar suas reais necessidades, o que permite o estabelecimento de um elo de confiança, fazendo deste serviço e desta equipe referência para o mesmo ${ }^{(6,12)}$.

Para o atendimento integral ao portador de transtorno mental é importante a existência de uma estrutura que viabilize tais ações: trata-se do reconhecimento de situações que produzem novos sujeitos de direito e novos direitos para os sujeitos ${ }^{(3)}$. Prestar assistência e gerar saúde para pessoas em sofrimento é um ato de busca e resgate da integralidade do sujeito.

A oferta de cuidados às demandas de saúde mental no PSF tem o objetivo de melhorar a qualidade de vida dos usuários, familiares e do ambiente através do incremento da autonomia e empoderamento de todos os envolvidos - sujeito e família ${ }^{(2)}$. Para que esse objetivo seja alcançado, a família e a comunidade devem ser aliadas do serviço de saúde no cuidado a essa demanda, que a partir da reforma psiquiátrica não mais é direcionada para o hospital psiquiátrico, mas permanece no domicílio, convivendo em família e comunidade, mesmo quando em tratamento em dispositivos de assistência comunitária como os CAPS ou outros.

Para isto, é necessária uma mudança que 
coloque em prática uma potente atitude de comunicação social que envolva os atores sociaisMinistério da Saúde, Secretarias Estaduais e Municipais, Conselhos de Saúde, Universidades, mídiae que permita desenvolver uma compreensão abrangente do que significa o PSF como estratégia de organização do SUS e a integralidade como eixo norteador de suas práticas ${ }^{(1,5)}$.

\section{O processo de trabalho das equipes}

Os elementos do processo de trabalho são o próprio trabalho, o objeto, meios e finalidades. Estes elementos são marcados por necessidades de um dado momento histórico, o que lhes imprime características próprias de um modelo assistencial ${ }^{(8)}$.

A partir de Mendes-Gonçalves ${ }^{(8)}$, consideramos que esses elementos apresentam alguma consistência prática no interior do processo de trabalho em saúde e possuem correspondência com as dimensões "externas" desse processo, o que indicaria, para este autor, os “modelos tecnológicos”. Numa reflexão que acompanha a noção de "modelo tecnológico" apresentada por este autor, consideramos que vivenciamos atualmente uma tentativa de superação do "modelo clínico" tanto no PSF quanto na atenção psicossocial.

Entretanto, essa "superação" representa, sempre, um processo contraditório de negação/ manutenção, pois se situa no cerne de um processo social complexo - a produção de cuidados de saúde que, historicamente, reproduz a lógica do capital e condiciona as atividades profissionais. Apesar disso, há sempre, nesse processo contraditório e histórico do "trabalho vivo em ato na saúde", uma micropolítica que pode provocar "ruídos, abrindo fissuras" e modificando os processos de trabalho instituídos. Essa micropolítica é o espaço das "tecnologias leves", constituído essencialmente pelo relacionamento entre o trabalhador e o usuário, no qual o primeiro pode utilizar, em algum grau, a sua autonomia para potencializar o compromisso ético com a saúde e a vida, por meio do acolhimento, da responsabilização e criação do vínculo ${ }^{(13)}$.

No PSF visa-se a apreensão de um objeto de trabalho que amplie o corpo individual, característico das práticas do modelo médico-curativo, para o indivíduo entendido como um conjunto dinâmico e complexo, nas dimensões fisiológicas, comportamentais, culturais, sociais, ambientais, familiares e afetivas.

$\mathrm{Na}$ atenção psicossocial o rompimento com o modelo psiquiátrico asilar visa uma ampliação e complexificação do objeto, meios e finalidades do trabalho, gerando transformação nas instituições de cuidado e nos saberes historicamente constituídos, por meio de relações intersubjetivas de trabalhadores e usuários nos grupos e comunidades ${ }^{(2-3)}$.

Essas duas experiências de superação em curso atualmente se originaram e se constituem na relação histórica e dialética que, simultaneamente, denuncia a crise de um modelo hegemônico (clínico previdenciário brasileiro que originou a Reforma Sanitária/SUS e médico-psiquiátrico excludente que originou críticas aos hospícios em todo o mundo ocidental no final do século XX), reproduz as formas de alienação do modo de produção capitalista nos seus processos de trabalho e, engendra novas formas de cuidado, incluindo novos cenários e pessoas que, por sua vez, conformam novas práticas, tanto no PSF como na atenção psicossocial.

\section{Objeto de trabalho e formas de identificação}

No PSF A o atendimento a todos os usuários era realizado segundo um rígido cronograma de consultas baseado nos programas ministeriais, numa padronização médico-assistencialista, cujo objeto de trabalho se confunde e se restringe ao corpo biológico, ao mesmo tempo em que o fragmenta segundo grupos pré-determinados: saúde da mulher, do adulto e da criança, entre outros.

Nesse processo, não havia uma agenda para a saúde mental. Quando havia demanda de usuários com transtornos mentais, estes eram "encaixados" nas consultas com o médico, no atendimento de "saúde do adulto”. Esta demanda era visível somente pela expressão de uma queixa física, ou quando necessitava de uma receita para adquirir psicotrópicos, ou um encaminhamento para entrar na rede especializada, como no exemplo em que uma usuária era conhecida pela equipe pelo consumo de bebida alcoólica, com crises de uso exagerado e abstinência, mas só era "atendida" nos momentos de crise, encaminhada para internação. Sobre isso, foi informado que:

\section{[...] a gente procura atender não só pensando nele} como um doente mental, mas como ele dentro de uma comunidade que tem [...] que pode ter um câncer de mama, que pode ter um câncer do colo do útero. Você tem que ficar preocupada com outras patologias, com outras doenças associadas 
(Profissional.10).

Esta delimitação do objeto de trabalho no corpo biológico configurava a única forma possível de identificação dos usuários com transtornos mentais e, em alguns casos, eram associados à periculosidade e a uma compreensão moral, remetida à esfera dos costumes sociais:

[...] não tem dinheiro para comprar carne, mas pra garrafinha tem [riso] [...] eu tenho um que o pai é usuário de droga e é alcoolista também, a mãe bebe, vende as coisas, as crianças já estão se prostituindo com nove, dez anos. Aí bate nas crianças, sem contar que bate na mulher, bate em todos os filhos, esses dia o rapaz arremessou a mulher no muro. Quando eles melhoram você conhece [...] que são geralmente pessoas que bebem e quando tá são é bom, é bonzinho, conversa tudo com a gente. Agora se tiver bêbado não adianta nem chegar, eles só xingam, jogam as coisas e [...] se tiver faca, eles entram na faca! (Profissional.8).

Eles brigam entre irmãos, só falta matar os irmãos [...] aí a gente tem medo de entrar e levar [...] (Profissional.7).

Essas falas, baseadas em intervenções empíricas e no senso comum, refletem dificuldades teórico-práticas de abordagem que não são valorizadas pelas equipes no sentido de superação. A necessidade de capacitação, neste caso, é inicialmente, a de reconhecer a situação como demanda de saúde, ou seja, o próprio objeto de trabalho ${ }^{(5,14)}$.

No PSF A os profissionais não sabiam relatar o número de casos de transtornos mentais e abuso e dependência de drogas na comunidade, pois esta identificação não fazia parte do trabalho da equipe, apesar de ser unânime entre eles a percepção de muitos casos naquela comunidade. Não eram realizadas ações sistemáticas de identificação, planejamento ou atendimento a essa clientela e, na vigência de atendimento específico, demandado pela presença do usuário na unidade, remetia-se ao médico os procedimentos de prescrição medicamentosa e encaminhamento para serviços especializados. Embora tenha sido realizado um levantamento, após a capacitação, de "busca ativa” dessa clientela, mediante um instrumento padronizado, este levantamento foi pontual e interno na unidade, pois saúde mental não era num "programa" que se fizesse relatório mensal e se avaliasse os dados e indicadores, seja pela equipe, seja pelos gestores locais.

Ao contrário do que foi observado no PSF A, a equipe do PSF B organizava seu trabalho de atendimento e acompanhamento dos casos de transtornos mentais através da "busca ativa" realizada pelos ACS e, uma vez identificada uma pessoa, os ACS discutiam com a família, cliente e demais integrantes da equipe, a necessidade e importância do acompanhamento. Após avaliação, o portador de transtorno mental e sua família eram acompanhados pelos ACS e enfermeiro através de formulário padronizado -Ficha B-, implantado após a capacitação. O acompanhamento dos casos era discutido nas reuniões semanais e valorizado, como pode se observar no relato:

[...] depois da Ficha B, a gente passou a acompanhar melhor, porque o enfermeiro tem uma, [...] e a ACS também, e através das perguntinhas que ele vai ver se consultou. Por que tem o de hanseníase, de gestante, de tuberculose, e agora tem a de doentes mentais, para que ele não caia no esquecimento (Profissional.12).

Destacam-se o trabalho e empenho da equipe em dar visibilidade às necessidades de saúde da comunidade, inclusive os transtornos mentais, por meio de abordagem familiar, e o ineditismo desta ação no município estudado ${ }^{(14)}$. Entretanto, observa-se que as necessidades de saúde identificadas pela equipe limitam-se à solução de problemas manifestos relacionados às patologias, em sua maioria aquelas inscritas nos programas ministeriais.

Cabe ressaltar que nos dois PSF havia dificuldade para identificação de dependentes químicos e alcoolistas que, em grande medida, eram inacessíveis para abordagem, pois há risco social envolvido e isto resulta que os ACS, responsáveis pelo trabalho de identificação, se afastem por medo:

[...] aqui tem uma porcentagem muito grande de famílias envolvidas com drogas; se vai alguém preso pode falar que foi a gente que falou. Já teve um caso assim aqui. Deu a maior confusão (Profissional.15).

O uso dos formulários padronizados (busca ativa e Ficha B) permitiu à equipe do PSF B o desenvolvimento de ações de saúde mental junto à 
comunidade, impedindo que pessoas em sofrimento mental permanecessem despercebidas, e levantando entre os profissionais questionamentos de como trabalhar, abordar e cuidar destas pessoas e suas famílias. A equipe apontou a necessidade de maior investimento em capacitação para qualificação do seu trabalho, uma vez que se sentem despreparados para conduzir alguns casos identificados e não têm apoio de outros serviços de saúde mental.

Esta emergência de conflitos e dúvidas entre os profissionais é mobilizadora para a conformação de novas formas de cuidado em saúde mental, pois o movimento de superação dos saberes e práticas psiquiátricas asilares requer uma disponibilidade técnica, ética e política dos profissionais para produzirem práticas reabilitadoras e emancipatórias, que visam o incremento da autonomia dos usuários ${ }^{(15)}$.

Compreendemos as modificações incorporadas em um PSF estudado, como uma das "fissuras" empreendidas no processo de construção da mudança de modelo assistencial. Apesar de tímida, a identificação de portadores de transtorno mental de modo sistemático numa unidade de PSF é algo que modifica a realidade das práticas de atenção à saúde no nível primário, no município e aponta uma contradição: a ausência de cuidado aos portadores de transtorno mental no rol de procedimentos de atenção à saúde do PSF.

\section{Organização do trabalho: mediação entre objeto, instrumentos e finalidades}

A partir da constituição do objeto de trabalho há a construção abstrata, idealizada, de um resultado ou finalidade, fazendo-se necessário a utilização de instrumentos ou meios de trabalho que também são criados mediante a intencionalidade do processo ${ }^{(8)}$.

A equipe do PSF A fazia, predominantemente, um recorte de objeto de trabalho no corpo biológico e, consequentemente, a finalidade das intervenções oriundas de problemas mentais era remetida para o atendimento especializado, como se observa na situação descrita:

[...] o profissional $n^{\circ} 1$ me mostrou a sua conduta de atendimento a um homem que faz uso há 10 anos de haloperidol ${ }^{\circledR}$, tegretol ${ }^{\circledR}$ e diazepam $^{\circledR}$ : encaminhamento ao Ambulatório de Psiquiatria para continuidade de uso das medicações e pedido de eletroencefalograma, pois o paciente desejava ser aposentado (RO).

Neste PSF os registros nos prontuários eram escritos predominantemente pelo médico acerca de tratamento de doenças físicas. Em relação à saúde mental, somente foram identificados registros de encaminhamentos ao psiquiatra e prescrição de medicamentos psicotrópicos. A centralidade do trabalho do médico é marcada e ratificada pelos demais:

[...] para resolver esses problemas [de transtornos mentais] tem o médico (Profissional.3).

[...] só que o doutor [médico] ele resolve o problema, ele é que resolve a maioria dos problemas que tem aqui (Profissional.5).

A divisão do trabalho no PSF A se dá principalmente pela hierarquização, somente o médico podia fazer anotações nos prontuários. As informações que os ACS julgavam importantes eram primeiramente relatadas para o enfermeiro que as repassava oralmente para os demais membros da equipe. $\mathrm{O}$ compartilhamento de estratégias na equipe e intersetoriais, na comunidade, necessários para a atenção psicossocial no $\operatorname{PSF}^{(15)}$ não foi observado nesta equipe. A relação de autoridade também marcava a abordagem familiar, que era vista como tendo o dever de cuidar do paciente, e não parceira nesse cuidado:

\section{[...] só interna se tiver assim em estado [...] porque senão agora é obrigado a família cuidar (Profissional.4).}

[...] é obrigado a cuidar [...] é [...] a família é que tem que acompanhar (Profissional.3).

Essa dificuldade de abordagem familiar pelas equipes de saúde foi construída historicamente e é observada também em outros contextos ${ }^{(4)}$.

No PSF B o registro do acompanhamento dos casos de transtorno mental era realizado sistematicamente e as Fichas B arquivadas junto com os relatórios; na época havia 35 casos em acompanhamento. Nos relatórios escritos pelos ACS e acompanhados pelo enfermeiro, eram registrados mensalmente a ocorrência de surtos ou crises, consultas com psiquiatra e uso de medicamentos, uso de drogas lícitas ou ilícitas, internações e alterações do comportamento. 
Apesar do acompanhamento ainda ter como foco a constatação do uso regular das medicações psicotrópicas e da regularidade das consultas médicas, ambas características do modelo biomédico, destacase a responsabilização da equipe com a demanda em saúde mental e sua busca por incorporar outras formas de cuidado, denotando aproximação à integralidade do cuidado.

Nesta unidade, as visitas domiciliares às pessoas e famílias em acompanhamento eram feitas semanalmente ou conforme a necessidade demandada pelo ACS, pela família ou pelo próprio usuário. Neste caso observamos que os profissionais tinham na família um aliado nos cuidados, o que no campo da reforma psiquiátrica é um valioso instrumento para a assistência de base comunitária ${ }^{(13)}$.

Em relação ao objetivo das ações assistenciais de saúde mental, no PSF B havia planejamento e acompanhamento visando a prevenção de crises, por meio de consultas periódicas e uso de medicamento prescrito. Enquanto no PSF A, a crise que demandava o momento de atenção à pessoa em sofrimento mental, o que tendia a desencadear ações de curta duração e especializadas, desconsiderando a necessidade de planejamento e acompanhamento no território.

Consideramos que, apesar de ainda focado no modelo clínico, no PSF B havia planejamento e práticas que denotam importante passo na incorporação de ações que visam a inclusão de portadores de transtorno mental nas práticas, enquanto no PSF A, as raras intervenções no campo da atenção à saúde mental eram remetidas para atendimento especializado. Dell'Acqua e Mezzina ${ }^{(16)}$ consideram este tipo de abordagem como o ponto máximo da simplificação de uma relação onde a complexidade do sofrimento de um sujeito é reduzida a um sintoma, e o serviço de saúde percebe, reconhece e se equipa para oferecer um modelo de simplificação do próprio sintoma, sem jamais "se colocar em crise" frente às reais demandas de atenção em saúde mental. A forte influência da indústria farmacêutica nas práticas de assistência à saúde desde a formação dos profissionais é significativa neste processo de medicalização e especialização.

Mesmo após o investimento da gestão em capacitação já realizado, não havia sistematização da identificação e/ou acompanhamento da demanda de saúde mental nos processos de gestão municipais, assim, a realização ou não das ações neste sentido estavam relacionadas aos limites, potencialidades e interesses das equipes, sem compor um planejamento institucional ou gerencial do SUS local. Desse modo, o histórico distanciamento entre a atenção primária e a saúde mental ${ }^{(2-3,6)}$ tem poucas possibilidades de ser superado. A necessidade de que gestores de saúde se comprometam com essas mudanças é fundamental e ainda apontada em processos tímidos, no nível federal da gestão do SUS, distante da realidade estudada ${ }^{(17)}$.

\section{A relação com os outros níveis da rede assistencial de cuidados em saúde mental}

Tanto a Reforma Sanitária como a psiquiátrica enfatizam a assistência de base comunitária, a participação do usuário no seu cuidado à saúde, e, entre seus objetivos, busca-se a formação de uma rede de serviços que prioriza a promoção da saúde e a prevenção de doenças ${ }^{(2)}$.

A necessidade dessa rede no campo da atenção à saúde mental é proposta por organismos internacionais como a OPAS/OMS ${ }^{(18)}$ e prevista no SUS ${ }^{(19)}$.

O PSF surge neste contexto de transformações e, por sua proximidade com as famílias e a comunidade, tornou-se um campo propício para promover saúde e trabalhar a saúde mental ${ }^{(2-3)}$. Atualmente a política de saúde nacional aponta diretrizes para que a rede de cuidados em saúde mental seja de base territorial a partir da articulação entre o PSF e CAPS. Tal articulação se produz na forma de co-responsabilização dos casos, intervenções conjuntas junto às famílias e comunidade e na forma de supervisão e capacitação ${ }^{(17,19)}$.

As duas unidades estudadas tinham como referência especializada de saúde mental um CAPS do tipo I que, na época da coleta dos dados, atendia apenas no período matutino e com equipe menor que a mínima prevista na normatização destes dispositivos ${ }^{(2)}$.

Essa redução de pessoal e de horário limitava a capacidade de atendimento, sendo insuficiente para a demanda e dificultava a criação de vínculo entre os PSF e o CAPS, explicitada nos relatos:

\section{[...] o problema é quando a ACS liga lá prá marcar} não é tão fácil assim como falam entendeu. [...] a demanda deles também é grande. Às vezes a gente quer agendar naquela época que a gente está precisando, mas eles também não tem como e acaba não agendando, agendando mais para frente aí o paciente acha que ele não precisa mais porque já melhorou e não vai (Profissional.14).

Eu sei que eu tenho que procurar o CAPS, mas aí 
eu procuro e não tem retorno (Profissional.15)

[...] porque o CAPS disse na época que eles iam ajudar, que a gente ia fazer, ia levar, eles iam acompanhar, mas a coisa mais difícil é conseguir uma consulta lá (Profissional.4)

O funcionamento deste serviço de referência se mostrou descontinuado e desarticulado no cuidado comunitário junto aos profissionais dos PSF. Ainda absorveu no seu atendimento a lógica da fragmentação e especialização do cuidado como demonstra o seguinte relato:

[...] liguei no CAPS para saber como poderia encaminhar uma pessoa alcoolista em crise e vítima de maus tratos familiares, porém uma mulher que se identificou como psicóloga me informou que eles só atendem casos de esquizofrenia, e que eu procurasse o CAPSad (álcool e drogas, localizado em região distante do PSF] (RO).

Este tipo de atenção fragmentada tem como conseqüência o "abandono" da comunidade, pois ao selecionar os problemas com base em uma especialidade, ou pior, segundo um tipo de "doença mental”, as pessoas são abandonadas a si mesmas, com seus problemas. O vínculo terapêutico é muito precário e a responsabilização não é clara ${ }^{(13,16)}$.

Ressaltamos a importância de compreender o processo de trabalho na dialética de conformação macro e micro-estrutural: os sujeitos - trabalhadores e pacientes/famílias - são simultaneamente determinados e determinantes de sua condição sóciohistórica. Vivem e trabalham em condições determinadas, mas são, também, agentes de transformação dessa realidade. As experiências de trabalho e cuidado observadas no PSF B, certamente, se constituem numa realidade concreta que, modificando o modo de trabalho/cuidado, também modificam os agentes envolvidos nesse trabalho/ cuidado - trabalhadores, usuários e familiares.

O desenvolvimento de ações de saúde mental no PSF, junto à comunidade, representa importante contribuição para a educação em saúde compromissada com a construção da atenção psicossocial $^{(5,14)}$, entretanto, esse movimento de mudança de práticas apresenta a necessidade de capacitação de trabalhadores e gestores, pois mudança de modelo de atenção não se faz sem planejamento e avaliação de ações e serviços coerentemente articulado.

\section{CONSIDERAÇÕES FINAIS}

As duas unidades estudadas representam diferentes experiências de trabalho para o processo de construção das ações de saúde mental na saúde da família. Essa diferença é determinada, entre outros fatores, pelo pouco investimento de trabalhadores, gestores e sistema formador na mudança de modelo assistencial no PSF e na atenção psicossocial, que requer desconstruir o histórico distanciamento entre as práticas psiquiátricas excludentes e a atenção primária à saúde.

A precariedade de recursos materiais e físicos das unidades não são facilitadores das ações de atenção psicossocial; uma unidade utiliza tecnologia para identificação e acompanhamento sistematizado da clientela portadora de transtorno mental, o que sinaliza importante passo para a construção da inclusão de pessoas e famílias em sofrimento mental no processo de trabalho/cuidado do PSF.

A precariedade e descontinuidade da rede especializada em saúde mental dificultam o atendimento no PSF de situações que requerem articulação com os outros níveis da rede de saúde no município.

O investimento municipal realizado por meio da capacitação, embora restrito, repercutiu na elaboração de instrumentos que permitem a sistematização de cuidado aos portadores de transtorno mental no PSF (Roteiro de "busca ativa" e "Ficha B de saúde mental"). Esses instrumentos foram utilizados em uma unidade e, desse modo, iniciou-se um processo de crítica a partir da prática, para a consolidação de estratégias assistenciais no cuidado de portadores de transtornos mentais no PSF. Apesar de ainda reproduzir um modelo focado na doença, consideramos que esse movimento é significativo para a abordagem à saúde mental nos PSF do município estudado, e não tem recebido apoio dos gestores locais para a sua continuidade.

\section{REFERÊNCIAS}

1. Cunha, GT. A construção da clínica ampliada na atenção básica. São Paulo: Hucitec; 2005.

2. Oliveira AGB, Vieira MAM, Andrade SMR. Saúde mental na Saúde da Família: subsídios para o trabalho assistencial. São Paulo: Olho d'água; 2006.

3. Amarante P. Saúde mental e atenção psicossocial. Rio

Cogitare Enferm 2008 Out/Dez; 13(4):548-57 
de Janeiro: Fiocruz; 2007.

4. Rosa L. Transtorno mental e o cuidado na família. São Paulo: Cortez; 2003.

5. Lancetti A. Radicalizar a desinstitucionalizacão. In: Brasil. Ministério da Saúde. Conselho Nacional de Saúde. Caderno de textos de apoio da III Conferência Nacional de Saúde Mental. Brasília; 2001. p.84-89.

6. Büchele F, Laurindo DLP, Borges VF, Coelho EBS. A interface da saúde mental na atenção básica. Cogitare Enferm. 2006 Set/Dez;11(3):226-33.

7. Maragno L, Goldbaum M, Gianini RJ, Novaes HMD, César CLG. Prevalência de transtornos mentais comuns em populações atendidas pelo Programa de Saúde da Família (QUALIS) no município de São Paulo, Brasil. Cad Saúde Publ. 2006 Ago;22 (8):1639-48.

8. Mendes-Gonçalves RB. Tecnologia e organização das práticas de saúde. São Paulo: Hucitec/ABRASCO; 1994.

9. Bardin L. Análise de conteúdo. Lisboa: Edições 70; 2007.

10. Conil EM. Políticas de atenção primaria e reforma sanitária: discutindo a avaliação a partir da analise do Programa de Saúde da Família de Florianópolis, Santa Catarina, Brasil, 1994-2000. Cad Saúde Publ. 2002 (supl);18:191-202.

11. Mendes EV. A atenção primária à saúde no SUS. Fortaleza: Escola de Saúde Pública do Ceará; 2002. 92p.

12. Ministério da Saúde (BR). Secretaria Executiva. Núcleo Técnico da Política Nacional de Humanização. Humaniza SUS: acolhimento com avaliação e classificação de risco: um paradigma ético - estético no fazer em saúde. Brasília: Ministério da Saúde, 2004.

13. Merhy EE. Em busca do tempo perdido: a micropolítica do trabalho vivo em saúde. In: Merhy EE, Onocko R, orgnizadores. Práxis em salud. São Paulo: Hucitec; 1997.

14. Oliveira AGB, Ataíde IFC, Silva MA. A invisibilidade dos problemas de saúde mental na atenção primária: o trabalho da enfermeira construindo caminhos junto às equipes de saúde da família. Texto Contexto Enferm. 2004;13(4):618-24.

15. Oliveira AGB, Marcon SR. Modelo médico-psiquiátrico e psicossocial: implicações para o processo de trabalho de enfermagem em saúde mental. In: Oliveira AGB, orgnizador. Ensino de enfermagem: temas e estratégias interdisciplinares. Coletânea Tecnologias em Saúde e
Enfermagem. Volume 4. Cuiabá: EdUFMT, 2006. p.27-50.

16. Dell'acqua G, Mezzina R. Resposta à crise: estratégias e intencionalidade da intervenção no serviço psiquiátrico territorial. In: Amarante P, coordenador. Archivos de Saúde Mental e Atenção Psicossocial 2. Rio de Janeiro: Nau; 2005.

17. Ministério da Saúde (BR). Secretaria de Atenção à Saúde. Departamento de Atenção Básica. Coordenação Geral de Saúde Mental. Saúde Mental e a atenção básica: o vínculo e o diálogo necessários. Brasilia: MS, 2001.

18. Organização Mundial da Saúde. Organização Panamericana de Saúde. Relatório sobre a saúde no mundo - Saúde mental: nova concepção, nova esperança. Genebra: OMS, 2001.

19. Ministério da Saúde (BR). Secretaria de Atenção à Saúde, Departamento de Ações Programáticas Estratégicas. Saúde Mental no SUS: os centros de atenção psicossocial. Brasília: Ministério da Saúde, 2004.

20. Milhomem MAGC. O trabalho das equipes nos Centros de Atenção Psicossocial (CAPS) de Cuiabá-MT [dissertação]. Cuiabá (MT). Universidade Federal de Mato Grosso; 2007. 